\title{
FMVSS 210 NORMUNA GÖRE SÜRÜCÜ KOLTUĞU GELISTTIRILMESI
}

\author{
Ebru PIŞGiN* \\ Erol SOLMAZ
}

Alınma:05.02.2018; düzeltme: 16.03.2018; kabul: 06.04.2018

Öz: Bu çalışmada, emniyet kemeri çekme testi dayanımı hakkındaki Amerika düzenlemesi olan, FMVSS regülasyonuna uygun üç noktalı emniyet kemeri bağlantı barı tasarımı (ICP-InterConnect Point) ve koltuk konsolu tasarımı geliştirilmesi temel alınmıştır. Mevcut durumda ECE-R14 regülasyonu şartlarını sağlayan sürücü koltuğu geliştirilerek Amerika regülasyonu olan FMVSS 210'a da uyumlu hale getirilmesi amaçlanmıştır. Bu regülasyon gereği üç noktalı emniyet kemerinin iki bağlantı noktasının koltuk üzerindeki ICP Bar üzerinde bulunması gereklidir. Bu çalışmada sürücü koltuğu için bir çok ICP Bar tasarımı yapılmıştır. Ayrıca bu yeniliğin yanında tüm pazar müşterilerine cevap verebilmek için koltuk ve araç arasındaki ortaklaştırılmış bağlantı konsolu tasarımı yapılmıştır. Yapılan tüm ICP Bar ve Konsol tasarım çalışmalarının dizayn dondurma işlemi için bilgisayar ortamında yapılan kinematik ve yapısal analizleri, müşteri talepleri ve ergonomi açısından değerlendirilmiş, en uygun tasarım seçilmiştir.

Anahtar Kelimeler: Sürücü Koltuğu,FMVSS 210 Regülasyonları, Tasarım Geliştirme, ICP Bar Tasarımı, Ağır Ticari Araç Koltuğu

\section{The Truck Driver Seat Development According to FMVSS 210}

\begin{abstract}
This study concern about new design of three point seat belt anchorage bar (ICP-Inter Connect Point) and its adaptation on the seat and design development of common reinforced seat console. Main aim of this study, driver seat development with new ICP bar and new console according to FMVSS 210. This seat alredy suitable with ECE-R14 regulation but forces of ECE-R14 regulation lower than FMVSS 210 forces. There were made lots of design for ICP bar and console at the begining of the design study. This study was handled with kinematic and structure analysis, customer requests and ergonomy issues for choose the optimum design and make a design freeze. All of these datas were evaluated and optimum design selected. The seat was strengthened with new console structure and unified ICP bar.
\end{abstract}

Keywords: FMVSS 210 Regulation, Design Development, ICP Bar Design, Inter Connect Point, Truck Driver Seat

\section{GİRIŞ̧}

Günümüzde sürücülerin güvenliği ve rahatlığ1 hakkındaki endişelerin artması ile sürücü koltukları kritik konular listesinde ilk sıralara yükselmiştir. Eskiden ağır ticari araç sürücüleri için sadece bir kutu üzerinde bulunan minder manasına gelen sürücü koltukları, şimdilerde çelik iskeletlerle desteklenmiş oturma yerleri ve araç ile arasında şok sönümleyicilerin bulunduğu konfor ve güvenlik ekipmanı manasına bürünmüştür. (Deierlein, 2000)

1960 ve 1970 li yıllardan sonra koltukların gelişimi hızlıca artmıştır. Bu hızlı gelişim sonucunda günümüzde sürücü koltukları sürücünün ağırlığı ve aracın donanımına bağlı olarak

\footnotetext{
*Grammer Koltuk Sistemleri Sanayi ve Ticaret Anonim Şirketi, DOSAB Mustafa Karaer Caddesi, Bursa

** Uludağ Üniversitesi, Mühendislik Fakültesi, Otomotiv Mühendisliği Bölümü, Bursa

İletişim Yazarı: Ebru PİŞGİN (Ebru.Pisgin@grammer.com)
} 
yaklaşık $900000 \mathrm{~km}$ kullanımlara kadar dayanmaktadır. Modern koltukların pozisyonları sürücünün ağırlığı ve yüksekliğine göre otomatikolarak ayarlanabilir, bel ve yanlarda bulunan destekler ile omurga desteklenebilir, oturak eğiklik ve derinlik hareketleri ile de kalça ve bacaklara binen yükler hafifletilebilir. Ayrıca süspansiyonlar ve hava körükleri de uzun ve bozuk yollarda sürücüye konfor sağlarlar. (Deierlein, 2000)

Koltuk üzerinde pek çok ayarlama butonu yada kolu mevcut olabilir. Bu kontrol noktaları koltuğun yanlarında, önünde, konsolunda veya koltuğun herhangi bir yerinde mevcut olabilir. Koltukların üzerinde standart kontrol bölgesi olmadığı için sürücülerin bu kontrolleri nasıl kullanacağını öğrenmesi gerekmektedir. Bu kadar fazla özelliğin bulunması sürücülerin koltuk seçiminde karşılaştırma yapmasına neden olmaktadır.Başlıca karşılaştırılan özellikler; esneme özelliği, kızak stroğu, ileri/geri titreşim sönümleyici, iskelet montajı, oturak ve arkalık süngeri, arkalık yatırma ayarı, esneme kapatıcıları, oturak eğiklik ve derinlik ayarı, oturak süngeri formu, bel ve yan destekleri, kolçaklar, döner adaptör, kafalık yüksekliği, hafizalı yükseklik ayarı ve k1lıf malzemeleridir. (Deierlein, 2000)

Sürücü koltuklarının ergonomisi çok önemlidir çünkü koltuklar güvenlik için gerekli ekipmanlara, konfora ve verimliliğe sahip olmalıdır. Bugün ki teknoloji ile üreticiler koltuk tasarımlarını ergonomi ve konfor açısından rahatlıkla ele alabilirler. İyi bir koltuk için temel gereklilikler sürücünün postürünü kontrol edebildiği, oturma alanını destekleyen, omuzları destekleyen, kollarımızı destekleyen ve bukoltuk özelliklerinirahatça kullanabilmemizi sağlayan sistemlerdir. (Skydel, 2008)

Ağır ticari araç sürücüleri çok çeşitli ölçü ve ağırlıkta olabilirler. Bu yüzden bir çokantropometri çalışmaları yapılmış ve çeşitli sürücülerin kol, omuz, oturma yüksekliği, sırt yüksekliği, ağırlık, kalça genişliği gibi ölçüleri alınmıştır. Bu ölçümler ile koltuktaki basınç haritaları oluşturulmuş ve haritalar sünger yoğunluğunun belirlenmesinde kullanılmıştır.(Skydel, 2008)

Toplu taşıma araçlarında, kamyon, çekici gibi uzun yol araçlarında sürücü koltuklarında sürücülerin konforunu artıran birtakım donanımlar yer almaktadır. Söz konusu donanımların temelinde, koltuk pozisyonunu ayarlamaya yarayan kızak mekanizması, koltuk yüksekliğini ayarlamaya yarayan ve sarsıntıların bir kısmını absorbe etmeye yarayan süspansiyon sistemi bu donanımların başında yer almaktadır.

Trafik kazaları karşısında doğabilecek ölüm ve yaralanmaların engellenmesi amacı ile farklı yapılanmalarda emniyet kemeri tasarımları kullanılmaktadır. Söz konusu yapılanmaların en yaygın olarak kullanılanı üç noktadan destekli emniyet kemerleridir. Üç noktadan destekli emniyet kemerlerinde birinci, ikinci ve üçüncü destek noktası genellikle şasi üzerinden seçilmektedir. Emniyet kemerinin makara kısmı araç şasisine sabitlenmekte, şasi üzerindeki bir destek noktasından dönerek yine şasi üzerine sabitlenmiş bir kilitleme aparatına emniyet kemerinin tokasının sabitlenmesi ile güvenliği sağlamaktadır.

Bazı sürücü koltuğu yapılanmalarında söz konusu ikinci destek noktası sürücü koltuğu üzerinden yapılmaktadır. Bu yapılanmada sürücünün emniyet kemeri ile daha iyi kavranması sağlanmakta ve güvenliğin artırılması hedeflenmektedir.

Yukarıda bahsedilen özellikle modüler sürücü koltuklarında bütün emniyet kemeri mekanizması sürücü koltuğunun üzerinde yapılandırılması hedeflenmektedir. Özellikle emniyet kemeri makarası, ikinci destek noktası ve kilit mekanizması koltuk üzerinde olması durumunda sürücünün etrafındaki alan rahatlatılmakta ve kaza anında sürücünün daha iyi kavranarak zarar görmemesi hedeflenmektedir.

Söz konusu yapılanmalarda kaza anında emniyet kemerinin bağlantı noktalarına düşen kuvvetler dengelenememekte, aşırı kuvvete maruz kalan kızak mekanizmaları hasar alarak koltuğun yerinden oynamasına sebebiyet verebilmektedir. Bu durum da sürücü güvenliğini olumsuz etkilemektedir.

Sonuç olarak yukarıda bahsedilen tüm sorunlar, ilgili alanda bir yenilik yapmayı zorunlu hale getirmiştir.Çalışmanın ana amacı iki noktasını koltuk konsolu üzerinde iki sabit noktasını 
barındıran, güvenliği artırılmış sürücü koltuğu yapısını ortaya koymaktır. Çalışmanın bir diğer amacı, FMVSS 210 test kuvvetlerine dayanım sağlayan konsol yapısı ortaya koymaktır.

Çalışmanın bir diğer amacı üç noktadan destekli emniyet kemeri barındıran sürücü koltuklarında güvenliği artırmaktır.

\section{MATERYAL VE YÖNTEM}

MSG90.6 sürücü koltuğu ECE-R14 regülasyonuna sahiptir. Üç noktalı emniyet kemeri bağlantı noktalarının hepsi koltuk üzerinde mevcuttur. Koltuk üzerindeki bu noktalar ECE-R14 çekme testi kuvvetlerini karşılamaktadır. Regülasyona göre ölçüleri belirli alt ve üst çekme aparatları ile statik yükler koltuğa uygulanmaktadır. Şendeniz ve Öztürk (2014)

Alt ve üst çekme aparatlarının koltuk üzerindeki yerleşimive uyguladıkları kuvvetler Şekil 1 ve Şekil 2' de gösterilmiştir.

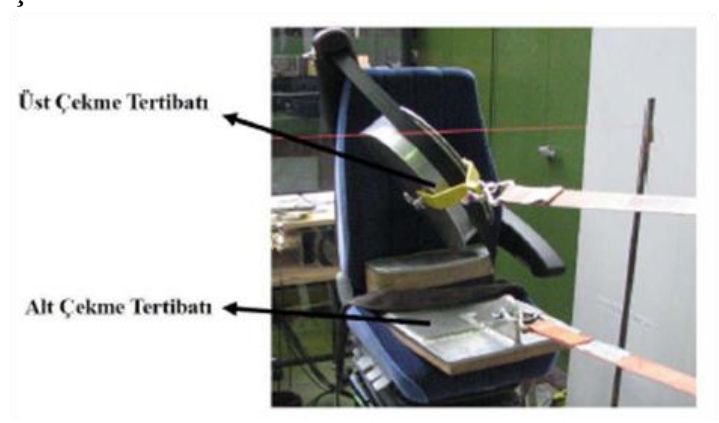

Şekill:

ECE-R14 alt ve üst çekme blokları (United Nations, 2003), Şendeniz ve Öztürk (2014)

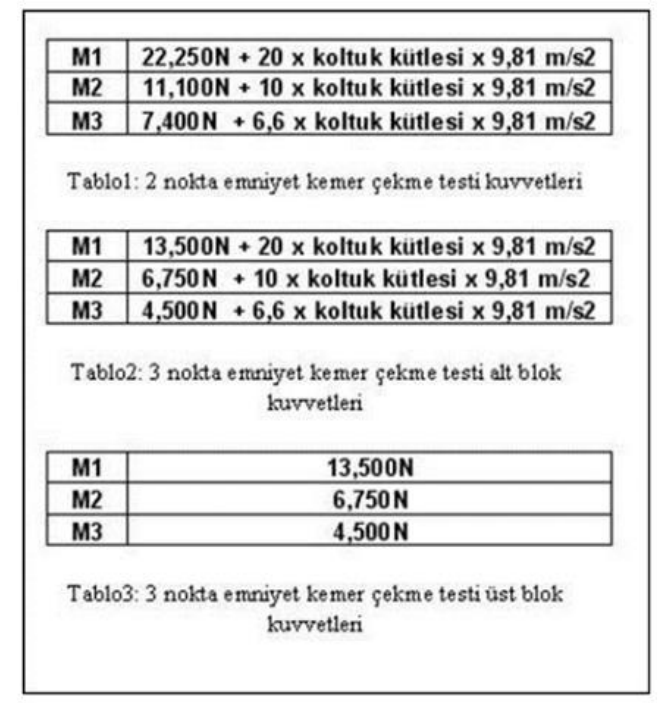

Şekil2:

ECE-R14 alt ve üst çekme blokları (United Nations, 2003)

MSG90.6 tasarım, fonksiyon ve dayanıklılık açısından müşteriler tarafindan çok tercih edilen bir ürün ailesidir. Bu yüzden FMVSS 210 adaptasyonu için tercih edilerek temel tasarım olarak baz alınmıştır. Çalışma kapsamında mevcut koltuğun FMVSS 210 normuna göre güçlendirme çalışmalarında dizayn Catia programı kullanılarak geliştirilmiştir. Tasarlanan yeni yapının dayanımını görmek adına Hypermesh programında modellenmesi yapılıp, zamana bağlı explicit analizler Radioss çözücüsü ile gerçekleştirilmiştir.(Catia V5, 1994), (HyperWorks, 1985) 


\section{SÜRÜCÜ KOLTUĞU TASARIMI}

Tasarım aşamasına başlanırken ilk etapta hitap edilecek Amerika pazarının ihtiyaçları tasarım girdileri olarak esas alınmıştır. Bu koltuğun bir çok araçta kullanılabilmesi için koltuğun altında tüm araç bağlantılarına uygun konsol tasarımı öngörülmüş̧ür. $\mathrm{Bu}$ yüzden çekme testi analizleri yapılırken de en kötü koşulu yansıtacak bağlantı noktaları seçilerek çekme testleri gerçekleştirilecektir. Ayrıca koltuğun H noktasının da belirli bir yükseklikte olması gerektiği için pedestalın boyu yine bir tasarım girdisidir. Diğer bir tasarım girdisi de üç noktalı emniyet kemeri bağlantı noktalarıdır. Amerika da genelde emniyet kemerinin 3. noktası araçtan gelmektedir. Ayrıca koltukta toka ve kemer bağlantı noktaları da ICP bar diye adlandırılan bir mukavim profil yada mil üzerine bağlanmaktadır.

FMVSS 210 normunda koltuğa gelen kuvvetler, ECE-R14 e göre ciddi derecede artmaktadır. Bu yüzden koltuğun zemine yada pedestala bağlantısını sağlayan kızakların yüklere dayanması çok zordur. Bu yükü karşılayabilmek ve doğrudan kızağa gelen yükü hafifletmek için kızakların dışından iç içe geçme sistemi tasarlanmıştır. Bir tasarım girdisi olan pedestal ortaklaştırma çalışmalar için Amerika da ki mevcut araç bağlantılarının Benchmark çalışmaları yapılmıştır. Sonrasında bu konsolların tümünün tek bir konsolda toplanması için tasarım çalışması yapılmıştır. Tasarlanan konsol ile birlikte kızaklara gelen yükleri hafifletecek olan iç içe geçme sac sistemi de tasarlanarak koltuğun alt grubunun tasarımı oluşturulmuştur. $\mathrm{Bu}$ tasarım da kızaklar arada kalacak şekilde üst kızak kuvvetlendirici ve alt kızak kuvvetlendirici olacak şekilde iki adet sacdan oluşan iç içe geçme sistemi oluşturulmuştur. Şekil 3' de sistemin montajlı hali gösterilmiştir.

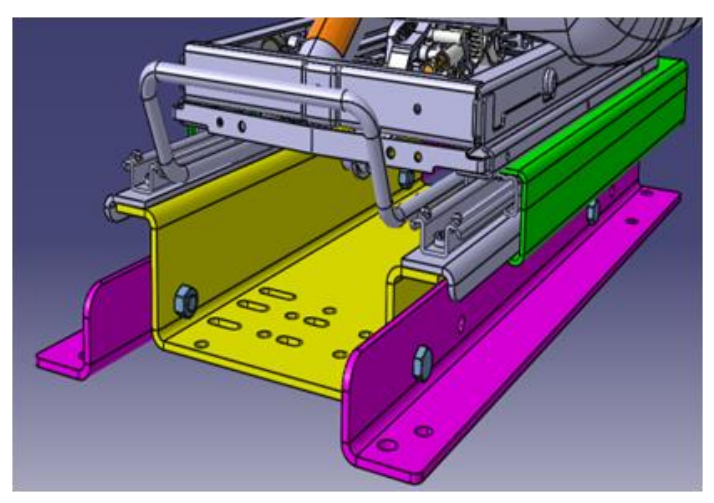

Sekil3:

Ortaklaştırılmış konsol ve iç içe geçme sistemi entegrasyonu (Catia V5, 1994)

Diğer bir tasarım girdisi olan ve emniyet kemerinin iki noktasının üzerinde bulunacağı ICP bar tasarımı için koltuğun retraktör bağlantı sacına bağlanabilecek mukavim bir kare profil ön görülmüştür. ICP bar tasarım aşamaları Şekil 4' de gösterilmiştir. 


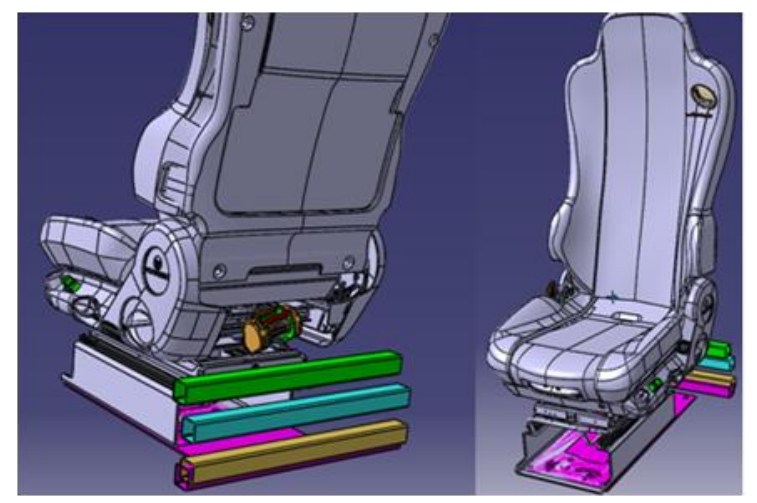

Şekil4:

ICP bar tasarım aşamaları (Catia V5, 1994)

Bu kare profilin açık uçlarına 7/16 UNF emniyet kemer cıvataları sıkılabilecek kaynak somunu yerleştirilmesi ön görülmüştür. Tasarımı sonrasında parçaların kaynaklanabilirliğini görmek için prototip çalışmaları yapılmıştır. Şekil 5' de 7/16 UNF kaynak somunu gösterilmiştir.

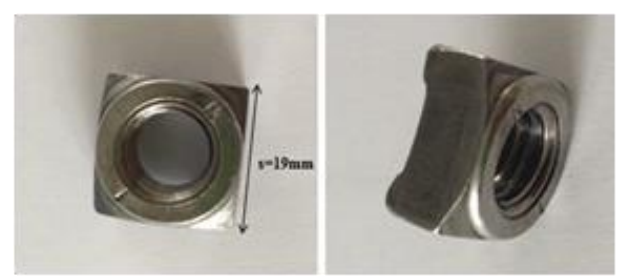

\section{Şekil5:}

7/16 UNF emniyet kemeri kaynak somunu

$19 \mathrm{~mm}$ genişliğe sahip kaynak somunu ve $30 \mathrm{~mm} \times 30 \mathrm{~mm}$ kare profil arasında, kaynak dikişinin yapılacağı boşluk 2,5mm olduğundan ve kaynak teli çapı kalınlığı $2 \mathrm{~mm}$ kullanıldığı için penetrasyon alanı boşluklu kalmıştır. Penetrasyon alanı kaynak işlemi için geniş olduğundan dolayı parçanın kaynak nüfuziyeti karşılaması gereken FMVSS 210 kuvvetlerine uygun değildir. Uygun olmayan kaynaklı grup Şekil 6' da gösterilmiştir.



Şekil6:

Kaynak dikişi uygun olmayan ICP bar tasarımı

Koltuğun arka kısmından yerleştirilebileceği ön görülen kare profilin koltuğa bağlanmasında kullanılacak ICP bar bağlantı sacı tasarımı da çeşitli aşamalardan geçmiştir. Üst 
esnemeye iki cıvata ile tutturulan bu bağlantı sacının mukavim bir yapıda olması yüksek çekme testi kuvvetlerine dayanabilmesi açısından çok önemlidir. Çeşitli bağlantı sacı tasarımları Şekil 7' de gösterilmiştir.

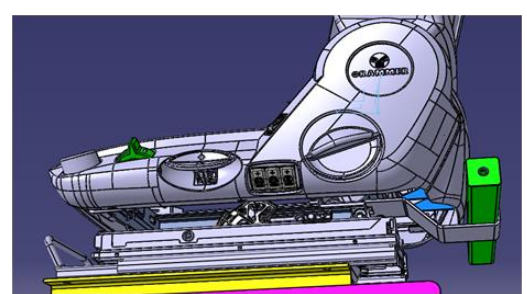

a.

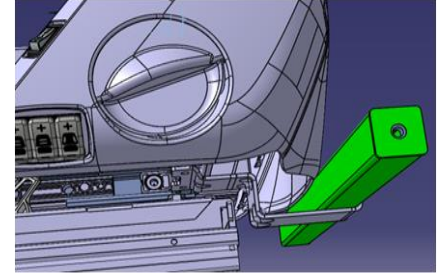

b.

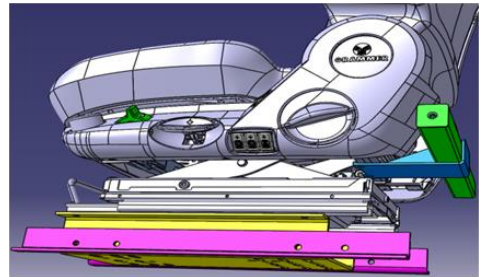

$c$.

\section{Sekil7:}

ICP bar tutucu sacı tasarımları (Catia V5, 1994)

a.1. tasarım b.2. tasartm c.3. tasartm (Catia V5, 1994)

Yukarıdaki gibi tasarımları yapılan çeşitli ICP bar bağlantı sacının kare profil ICP bar ile olan bağlantısı mukavim bir şekilde sağlanamamıştır ve bağlantı sacı uzunluğu fazladır. Ayrıca kaynak somunu kaynaklanan ICP barın tasarımının da kaynak normuna göre uygun olmamasından dolayı tasarım iyileştirmesi yapılmışıtır.

Yeni tasarımda daha kısa bir ICP bar bağlantı sacı ile bu saca kaynaklanabilecek içi dolu mil şeklinde bir ICP bar tasarlanmıştır. İçi dolu milin iki ucuna 7/16 UNF emniyet cıvatasına uygun diş açılarak emniyet kemerinin iki noktasının bağlantısı sağlanacaktır. Bu dizayn ile kaynak somunu ihtiyacı da ortadan kalkmıştır. Şekil 8' de mil şeklinde tasarlanan ICP Bar gösterilmiştir.

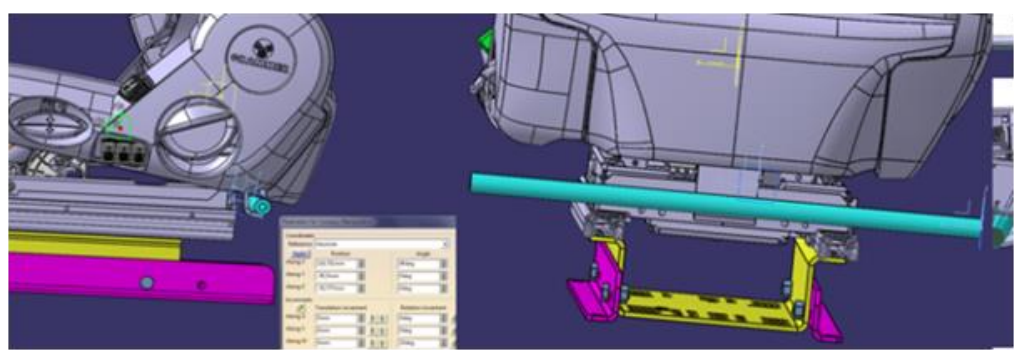

Şekil8:

İçi dolu mil şeklinde tasarlanan ICP bar (Catia V5, 1994)

Yukarıdaki gibi tasarlanan bağlantı sacının hem ICP bar ile olan bağlantısı hem de üst esneme ile bağlantısı olması gerektiğinden tasarım açısından kritik nokta sayısını artırmaktadır. Kritik nokta sayısının artması da çekme testi sırasındaki yük dayanımını azaltıcı yönde etki etmektedir.

Bağlantısı sayısının azaltılıp daha mukavim bir yapı elde etmek için ICP bar doğrudan koltuk üzerinde bir noktaya kaynaklanması düşünülmüş bunun için tasarım çalışmaları yapılmıştır.Bu çalışmalar sonucunda içi dolu mil şeklinde tasarlanan ICP barın oturak taşıyıcının arkasına kaynaklanması tasarlanmıştır. Şekil 9' daICP Bar ve koltuğun entegrasyonu gösterilmiştir. 

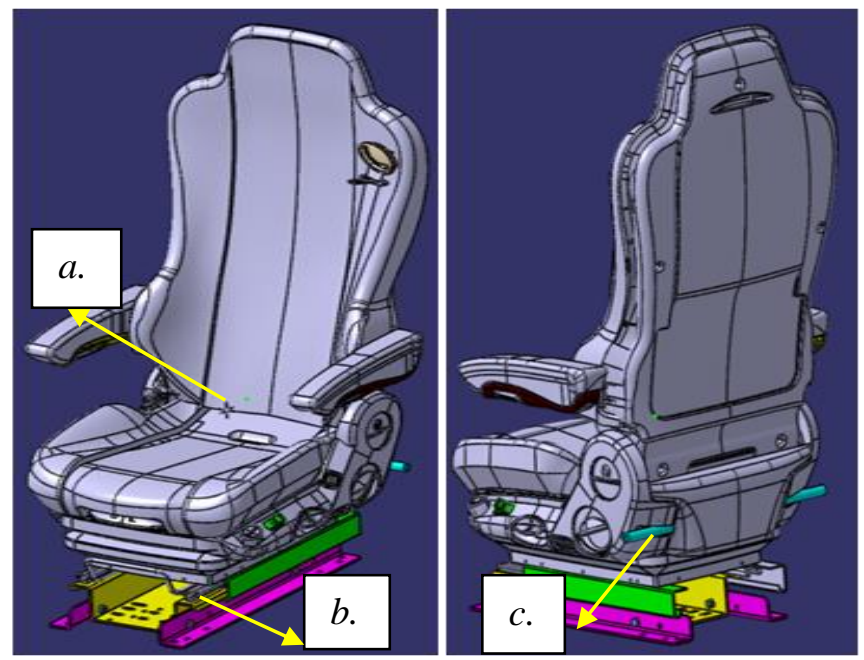

Şekil9:

Oturak taşılyıc ile yekpare ICP bar ve koltuğun entegrasyonu (Catia V5, 1994)

a.H noktası b.Pedestal c.ICP Bar (Catia V5, 1994)

\section{SÜRÜCÜ KOLTUĞU TASARIM DOĞRULAMA TEST VE SIMÜLASYONLARI}

Yapılan güçlendirmeler sonrasında analizler için model Hypermesh programında oluşturulmuştur. Ardından koltuğun gerçekteki ağırlığı hesaplanmıştır. Koltuk yapılan güçlendirmeler ve eklenen pedestal sonrasında $47 \mathrm{~kg}$ gelmektedir. Bu doğrultuda üst bloktan $13500 \mathrm{~N}$, alt bloktan $13500 \mathrm{~N}$ ve koltuk ağırlık merkezinin arka kısımdan da $9300 \mathrm{~N}$ luk bir yük uygulanacaktır. Şendeniz ve Pişgin (2016)

Koltuğa uygulanan kuvvetler şekil üzerinde aşağıdaki Şekil 10' da gösterilmiştir.

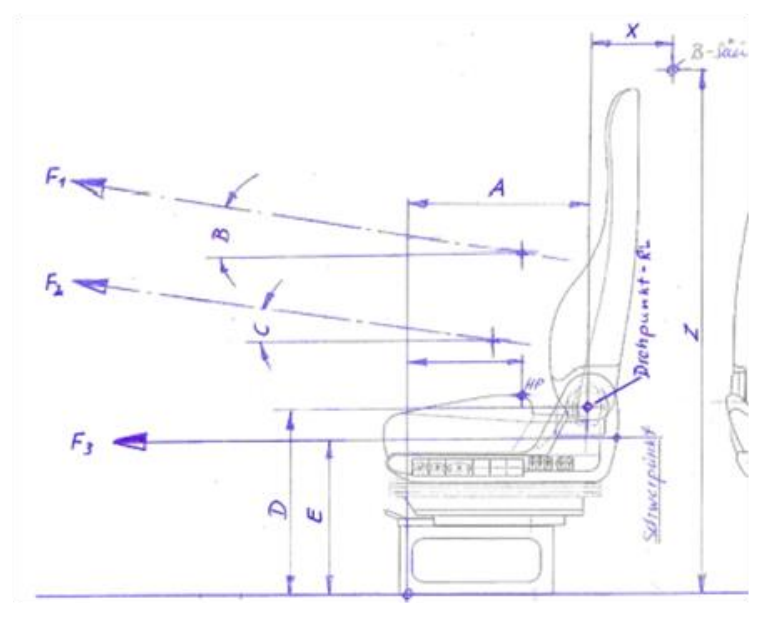

\section{Şekil10:}

Koltuğa uygulanan kuvvetler(F1:13,5 KN, F2:13,5 KN, F3:Koltuk ăğrlı̆̆ x 20) Şendeniz ve Pişgin (2016)

$\mathrm{Bu}$ hesaplamalar sonrasında Hypermesh programında kuvvetler girilmiştir. Hesaplanan kuvvetler zamana bağlı olarak 3 saniyede maksimuma ulaşıp, yapıya da 10 saniye boyunca etki edecek şekilde tanımlanmıştır. Şendeniz ve Pişgin (2016)

Hypermesh programında oluşturulan kuvvet eğrisi aşağıdaki Şekil 11' de gösterilmiştir. 




Hypermesh programında oluşturulan kuvvet eğrisi (HyperWorks, 1985), Şendeniz ve Pişgin (2016)

Yapının sonlu elemanlar modellemesi için 1 boyutlu rigid body elemanlar, 2 boyutlu shell elemanlar ve 3 boyutlu elemanlar seçilerek, toplamda 73406 eleman kullanılmıştır. Kaynak kısımları rigid eleman ile modellenmiştir. Shell elemanların kenar kısımlarına TRUSS2N elemanlar tanımlanıp kontakları görmesi sağlanmıştır. Aşağıda Şekil 12 ve Şekil 13' de kullanılan elemanların çeşitleri gösterilmiştir. Eleman seçimleri tamamlandıktan sonra yapının modellenmiş görüntüsü Şekil 14' de gösterilmiştir.

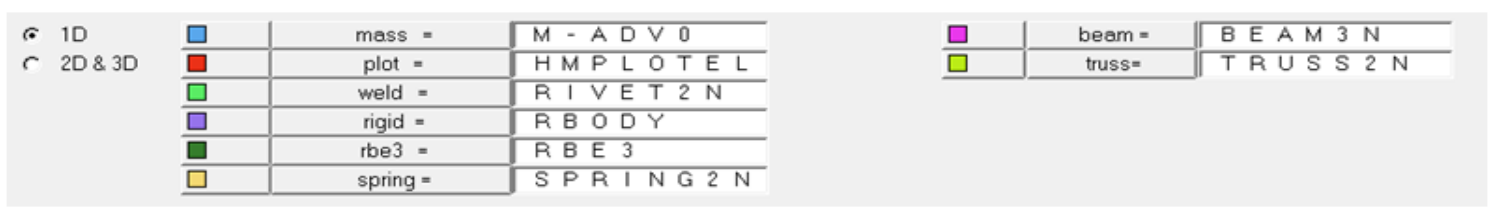

Şekil 12:

Modellemede kullanılan 1 boyutlu eleman tipleri (HyperWorks, 1985)



Şekil 13:

Modellemede kullanilan 2 ve 3 boyutlu eleman tipleri(HyperWorks, 1985)

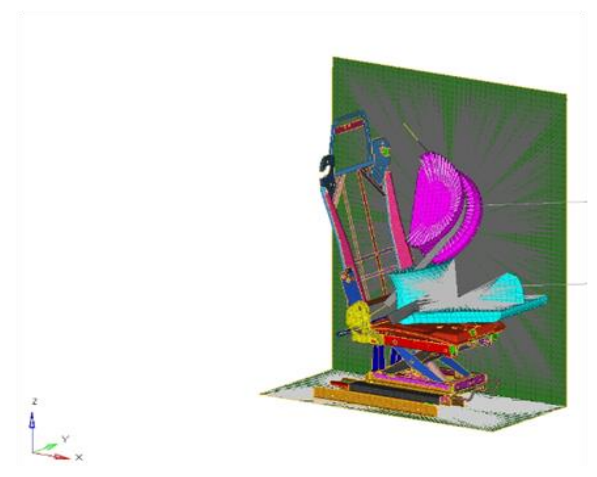

a.

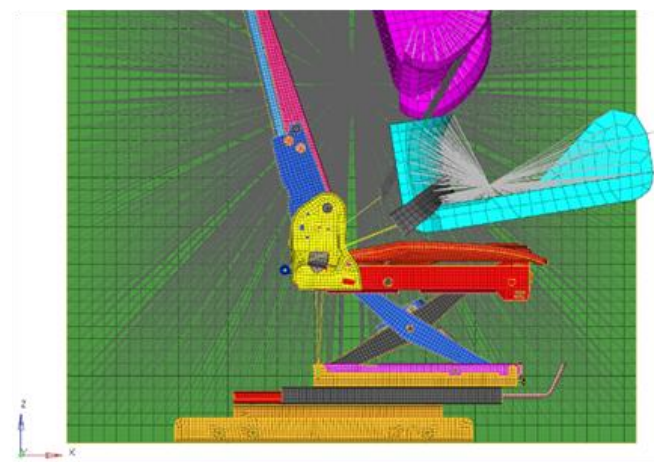

$h$.

Şekil 14:

Tasarımin sonlu elemanlar modellemesi (HyperWorks, 1985),

a.Model görüntüsü 1 b. Model görüntüsü 2 (HyperWorks, 1985), 
Koltuğa yapılan ilk analizler sonucunda tasarımın uygulanan kuvvetlere dayandığ görülmüştür. ICP bar üzerine binen yüklerden ICP bar da eğilmeler olmuş ancak yer değiştirme uygun değerlerdedir. Özellikle kızak kuvvetlendirici saclar üzerine gelen fazla yükler bu kuvvetlendirici sacların önemini göstermiştir. Kızak kuvvetlendirici saclar pedestalın kıvrımlı formuna tutunup, kopmayı ve yırtılmayı önleyerek sadece deformasyona uğramıştır. Bu sayede koltuk sonlu elemanlar analizini başarı ile geçmiş̧ir. Şendeniz ve Pişgin (2016)

Analizde elde edilen koltuk üzerindeki Von-Mises gerilme dağılımları Şekil 15' de gösterilmiştir.



Sekil15:

Koltuk üzerindeki Von-Mises gerilme dağllımlarl (HyperWorks, 1985), Şendeniz ve Pişgin (2016)

a.Gerilme dağılımları 1 b.Gerilme dağılımları 2 (HyperWorks, 1985), Şendeniz ve Pişgin (2016)

FEA analizi ile doğrulanan tasarıma göre test koltuğu üretilerek, gerçek FMVSS 210 testi için Amerika'da ki bağımsız bir laboratuara test koltuğu gönderilmiştir.

Amerika'da ki FMVSS 210 testi FMVSS 207 testleri ile bağlantılıdır.Bu yüzden öncesinde FMVSS 207 testi yapıldıktan sonra koltuğu FMVSS 207/210 yükü uygulanır.Bu ardışık testlerin kurulum şeması Şekil 16' da gösterilmiştir.(FMVSS, 1994)

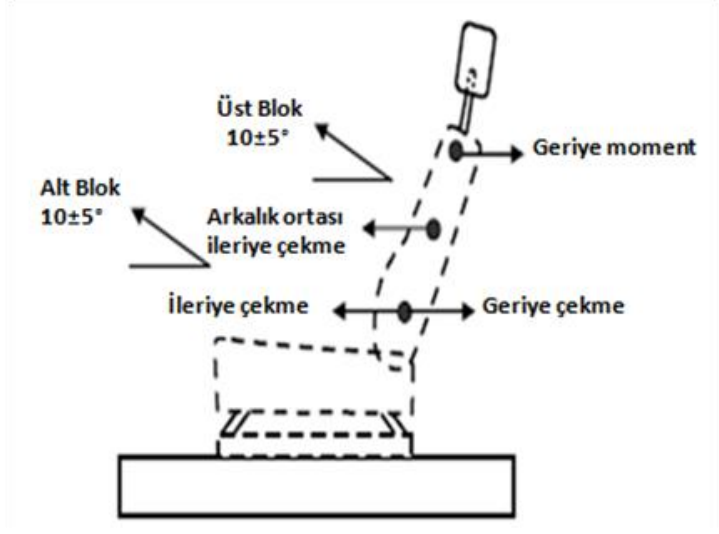

Şekil16:

207/210 ardışık testleri kurulum Şeması (FMVSS, 1994) 
Koltuğun bu homologasyona sahip olabilmesi için koltuğun üç ayrı 207 testinden sonrasında bir 207/210 testinden geçmesi gerekmektedir. Tablo 1' de bu dört ardışık testte uygulanan kuvvet değerleri gösterilmiş̧ir. (FMVSS, 1994)

Tablo 1. FMVSS 207/210 ardışık test kuvvetleri (FMVSS, 1994)

\begin{tabular}{|c|c|c|c|c|}
\hline $\begin{array}{l}\text { Test } \\
\text { No }\end{array}$ & $\begin{array}{c}\text { Test } \\
\text { Açıklaması }\end{array}$ & \multicolumn{2}{|c|}{$\begin{array}{l}\text { Max.Yükleme } \\
\text { (N) }\end{array}$} & Test Beklentileri \\
\hline A16005 & $\begin{array}{c}207 \\
\text { Geriye Moment }\end{array}$ & \multicolumn{2}{|c|}{$\begin{array}{c}736 \\
\text { (Max.Moment:394Nm) }\end{array}$} & $\begin{array}{c}\text { *FMVSS gerekliliklerini } \\
\text { karş1laması } \\
\text { * Yük profilini tamamlaması }\end{array}$ \\
\hline A16006 & $\begin{array}{c}207 \\
\text { Geriye Çekme }\end{array}$ & \multicolumn{2}{|l|}{9,275} & $\begin{array}{l}\text { *FMVSS gerekliliklerini } \\
\text { karş1laması } \\
\text { * Yük profilini tamamlaması }\end{array}$ \\
\hline A16007 & $\begin{array}{l}207 \\
\text { Arkalık Ortası İleriye } \\
\text { Çekme }\end{array}$ & \multicolumn{2}{|l|}{2,005} & $\begin{array}{c}\text { *FMVSS gerekliliklerini } \\
\text { karş1laması } \\
\text { * Yük profilini tamamlaması }\end{array}$ \\
\hline \multirow{3}{*}{ A16008 } & \multirow{3}{*}{$\begin{array}{c}\text { 207/210 } \\
\text { İleriye Çekme }\end{array}$} & Ağırlık Merkezi & 9,293 & \multirow{3}{*}{$\begin{array}{l}\text { *FMVSS gerekliliklerini } \\
\text { karş1laması } \\
\text { * Yük profilini tamamlaması }\end{array}$} \\
\hline & & Üst Blok & 13,371 & \\
\hline & & Alt Blok & 13,362 & \\
\hline
\end{tabular}

Test koltuğunun ağırlığı esneme kısmı $37 \mathrm{~kg}$, arkalık kısmı $10 \mathrm{~kg}$ olacak şekilde toplamda $47 \mathrm{~kg}$ olarak belirlenmiştir. Koltuğun ağırlık merkezi de bağlantı zemini 0 kabul edilerek ve yükseklik ayarı en üst konumdayken, $\mathrm{Z}$ ekseninde $308 \mathrm{~mm}$ olarak belirlenmiştir.

AşağıdakiTablo 2' de geriye moment testinin girdileri gösterilmiştir.

Tablo 2. Test A16005 Girdileri (FMVSS, 1994)

\begin{tabular}{|c|c|}
\hline \multicolumn{2}{|c|}{ TEST A16005 Girdileri } \\
\hline Koltuk Tipi: Geriye Moment \\
\hline Koltuk Fonksiyonu & Test Pozisyonu \\
\hline Araç Pozisyonu & Tam Arkaya \\
\hline Dikey Pozisyon & Tam Aşağıda \\
\hline Arkalık Açısı & $38^{\circ}$ geriye ayarlı \\
\hline H-Noktası & Tabandan 420 mm yukarıda \\
\hline Moment Kolu & H noktasından 514 mm yukarıda \\
\hline Yükleme Açısı & $0^{\circ}$ \\
\hline
\end{tabular}


Tablo 3'de geriye moment testinin yükleme profili gösterilmiştir.

Tablo 3. Test A16005 Yük Tablosu (FMVSS, 1994)

\begin{tabular}{|c|c|}
\hline \multicolumn{2}{|c|}{ Yükleme Profili } \\
\hline $\begin{array}{c}\text { Zaman } \\
\text { (Saniye) }\end{array}$ & $\begin{array}{c}\text { Yük } \\
\text { (N) }\end{array}$ \\
\hline 0 & 72 \\
\hline 5 & 726 \\
\hline 11 & 726 \\
\hline 16 & 0 \\
\hline
\end{tabular}

Tablo 3' de ki yükleme profiline ve Şekil 17' de bulunan Yük/Zaman grafiğine göre koltuk 5.saniyede ulaştığı maksimum yüke 6 saniye boyunca dayanmıştır ve böylece FMVSS gerekliliklerini yerine getirmiştir.



Şekil17:

Test A16005 Yük/Zaman grafiği (FMVSS, 1994)

Aşağıdaki Şekil 18' de koltuğun testten sonraki durumu gösterilmiştir.

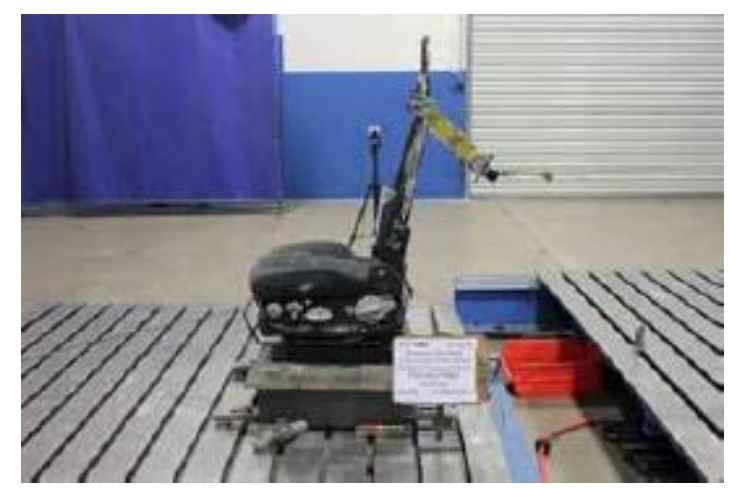

Şekil18:

Test A16005 Sonrası Koltuğun Durumu (FMVSS, 1994) 
FMVSS 207 ve 210 testlerinin ardışı uygulandığ 1 son test olan ileriye çekme testinin girdileri Tablo 4' de gösterilmiştir.

Tablo 4. Test A16008 Girdileri (FMVSS, 1994)

\begin{tabular}{|c|c|c|}
\hline \multicolumn{3}{|c|}{ TEST A16008 Girdileri } \\
\hline \multicolumn{3}{|c|}{ Koltuk Tipi: 207/210 İleriye Çekme } \\
\hline \multicolumn{2}{|c|}{ Koltuk Fonksiyonu } & Test Pozisyonu \\
\hline \multicolumn{2}{|l|}{ Araç Pozisyonu } & Tam Arkaya \\
\hline \multicolumn{2}{|l|}{ Dikey Pozisyon } & Tam Aşağıda \\
\hline \multicolumn{2}{|l|}{ Arkalık Açısı } & $38^{\circ}$ geriye ayarlı \\
\hline \multicolumn{2}{|l|}{ Koltuk Ağırlı̆̆1 } & $460,9 \mathrm{~N}$ \\
\hline \multicolumn{2}{|l|}{ Ağırlık Noktas1 } & tabandan $308 \mathrm{~mm}$ yüksekte \\
\hline \multicolumn{2}{|l|}{ Yükleme Açıs1 } & $0^{\circ}$ \\
\hline \multirow{3}{*}{$\begin{array}{c}\text { Emniyet Kemeri } \\
\text { Yuvarlanma Pozisyonu }\end{array}$} & $\mathrm{x}$ & arkalık dönme merkezinden $260 \mathrm{~mm}$ geride \\
\hline & $\mathrm{y}$ & koltuk merkezinden $390 \mathrm{~mm}$ yanda \\
\hline & $\mathrm{Z}$ & taban düzleminden $1165 \mathrm{~mm}$ yükseklikte \\
\hline \multirow{2}{*}{ Kemer Uzunluğu } & Alt Blok & $640 \mathrm{~mm}$ \\
\hline & Üst Blok & $1600 \mathrm{~mm}$ \\
\hline Kemer Tokası Uzunluğu & Alt Blok & $290 \mathrm{~mm}$ \\
\hline \multicolumn{2}{|l|}{ Yükleme Aç1s1 } & 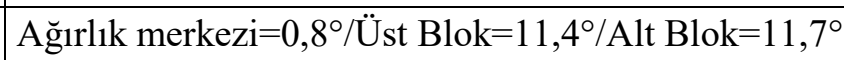 \\
\hline
\end{tabular}

Aşağıdaki Tablo 5' de bulunan yükleme profiline ve Şekil 19' da bulunan Yük/Zaman grafiğine göre koltuk 29. saniyede ulaştı̆̆ maksimum yüke 11 saniye boyunca dayanmış ve böylece FMVSS gerekliliklerini yerine getirmiştir.

Tablo 5. Test A16008 Yük Tablosu (FMVSS, 1994)

\begin{tabular}{|c|c|c|c|}
\hline \multicolumn{4}{|c|}{ Yükleme Profili } \\
\hline $\begin{array}{c}\text { Zaman } \\
\text { (Saniye) }\end{array}$ & $\begin{array}{c}\text { Ăğılı Merkezi Yükleri } \\
(\mathbf{N})\end{array}$ & $\begin{array}{c}\text { Alt Blok Yükleri } \\
(\mathbf{N})\end{array}$ & $\begin{array}{c}\text { Üst Blok Yükleri } \\
(\mathbf{N})\end{array}$ \\
\hline 0 & 921 & 1335 & 1335 \\
\hline 29 & 9218 & 13350 & 13350 \\
\hline 40 & 9218 & 13350 & 13350 \\
\hline 50 & 0 & 0 & 0 \\
\hline
\end{tabular}

Testlerden önce ve sonra çekilen resimler, koltuk üzerinde uygulanan kuvvetlerin ne kadar fazla kalıcı şekil değişimine sebep olduğunu göstermiştir. Koltuk üzerindeki bölgesel deformasyonlardan aşağıda örnekler gösterilmiştir. Koltukta meydana gelen deformasyonlardan örnekler Şekil 21' de gösterilmiştir. 


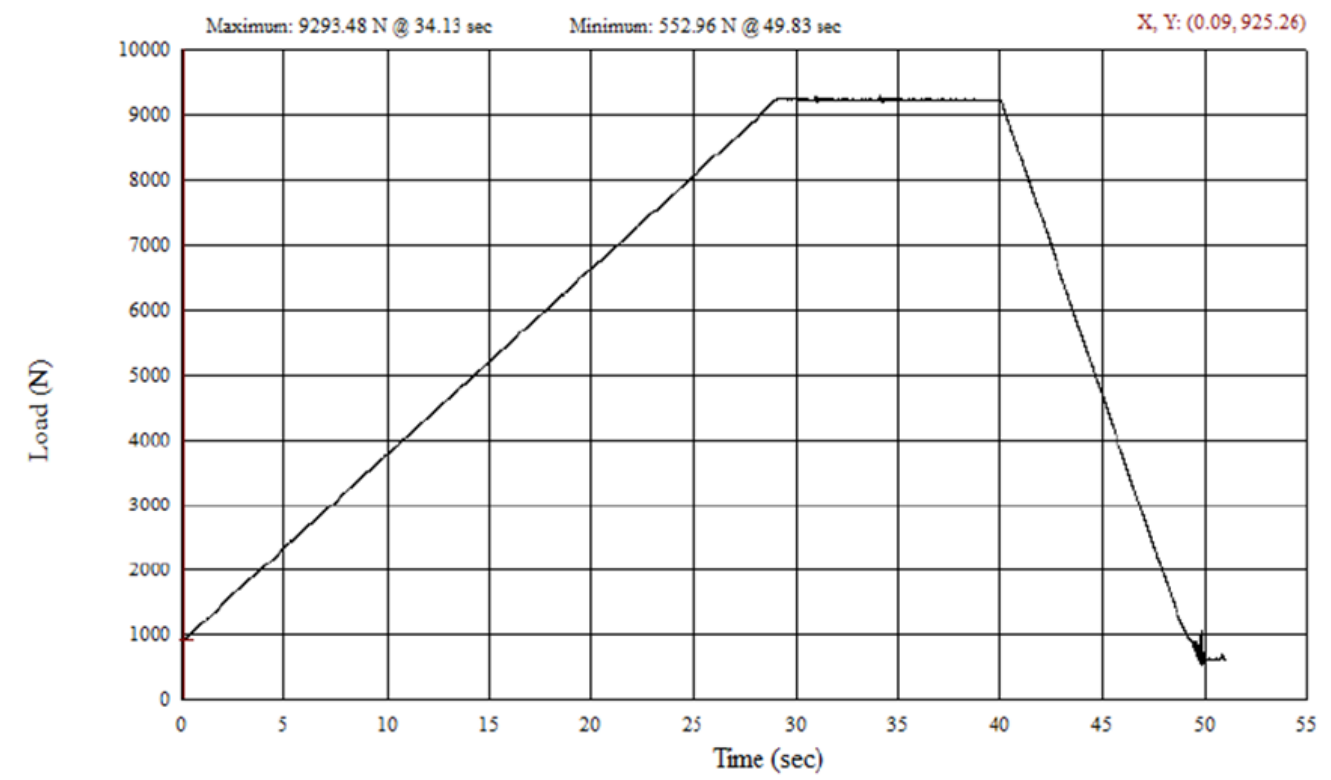

Şekil19:

Test Al6008 Yük/Zaman grafiği (FMVSS, 1994)

Aşağıdaki Şekil 20' de test sonrası koltuğun durumu gösterilmiştir.



Sekil20:

Test A16008 Sonrası Koltuğun Durumu (FMVSS, 1994)



$a$.



$b$.

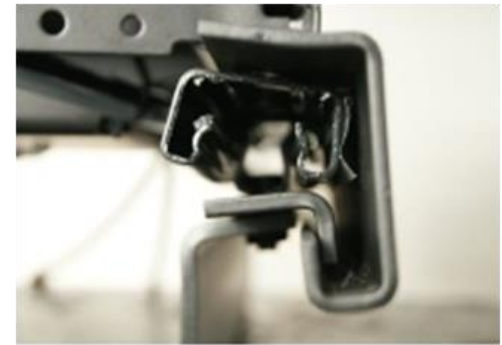

$c$.

Sekil21:

Konsol ve Destek saclarının șekil değişimi

a.Konsol ve destek sacları b.ICP Bar c. Iç içe geçme sistemi 
Koltuk belirlenen pozisyonlardaki yüklere gerekli süre boyunca dayanarak testlerden başarı ile geçmiş ve böylece tasarım doğrulama gerçekleşmiştir.

Aşağıdaki Şekil 22'de yeni tasarım sonucu elde edilen analiz sonuçları ile deneysel sonuçların karşılaştırması görülmektedir. Koltuk, çekme testinde FEA analizlerinde ön görülen şekil değiştirmede kalmıştır. İç içe geçme kızak sistemi ve ICP bar üzerinde düşen kuvvetleri karşılayarak koltuğun FMVSS 210 kuvvetlerine dayanmasını sağlamıştır. Böylece tasarım beklentileri karşılanmıştır.



Şekil 22.

Analiz sonucu ve deneysel sonuç karşılaştırması 1

Aşağıdaki Şekil 23'de, ICP bar üzerindeki emniyet kemer tokasının bağlı olduğu ucun, uygulanan kuvvete karşı nasıl şekil değiştirdiği gösterilmektedir. Analiz sonuçları ve deneysel sonuçlar birbirine yakın sonuçlar vermişlerdir.
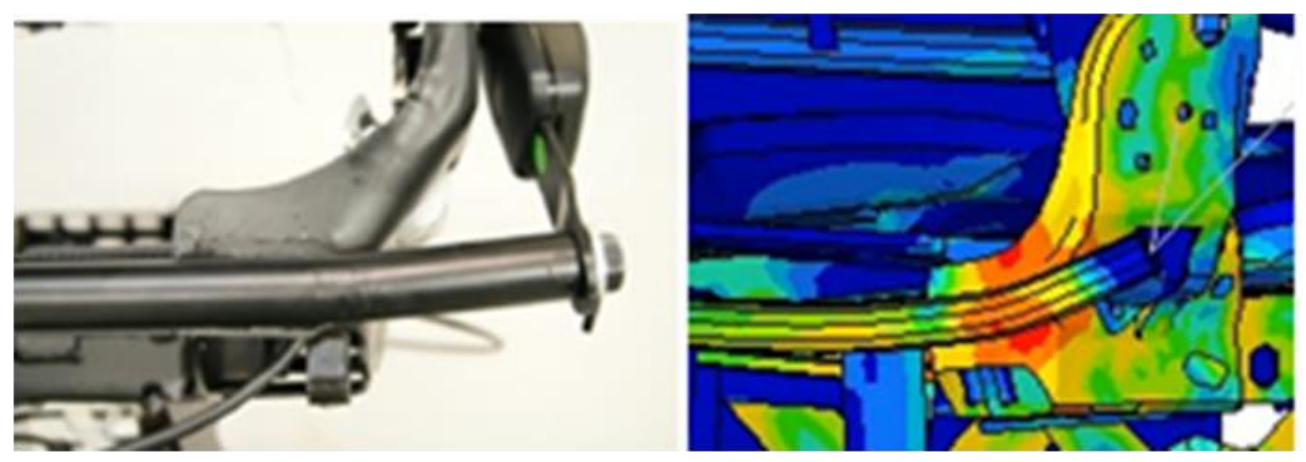

Şekil 23:

Analiz sonucu ve deneysel sonuç karşılaştırması 2

Aşağıdaki Şekil 24'de, iç içe geçme kızak sisteminin uygulanan kuvvete karşı nasıl şekil değiştirdiği gösterilmiştir. Önceki tasarımlarda kızakların doğrudan maruz kalarak hasara neden olan kuvvet, bu tasarımda kızak kuvvetlendirici saclar üzerine aktarılmıştır. Bu kuvvetlendirici saclar da kızak sisteminin FMVSS 210 kuvvetlerine dayanmasını sağlamıştır. 


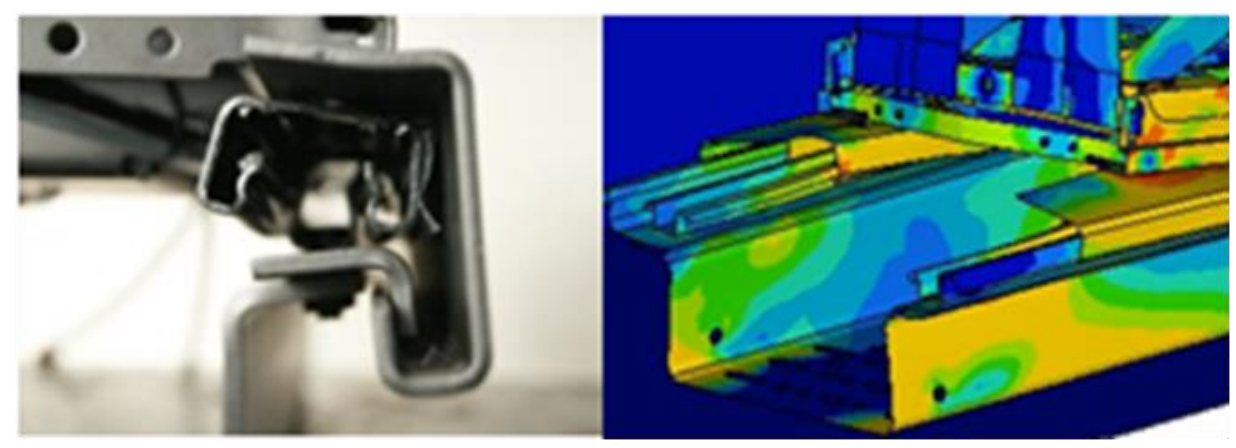

Şekil 24:

Analiz sonucu ve deneysel sonuç karşılaştırması 3

\section{SONUÇ}

Mevcut tasarımlarda kaza anında emniyet kemerinin bağlantı noktalarına düşen kuvvetler dengelenememekte, aşırı kuvvete maruz kalan kızak mekanizmaları hasar alarak koltuğun yerinden oynamasına sebebiyet verebilmektedir. Bu durum da sürücü güvenliğini olumsuz etkilemektedir.

Yapılan yeni tasarım, yukarıda bahsedilen problemleri ortadan kaldırmak ve ilgili alanda teknik bir yenilik yapmayı zorunlu kılmaktadır.

Bu çalışma sonucunda FMVSS 210 Amerika Standardı firma bünyesinde FEA ile iyi bir şekilde analiz edilmiştir. Bu yüklerin koltukta ne gibi hasar oluşturabileceği, nasıl bir güçlendirme yapılacağı; yapılan analizler sonucunda elde edilmiştir. Sonrasında numune koltuk bağımsız bir Amerika FMVSS laboratuarına gönderilerek koltuğun homologasyon sertifikası alınması sağlanmıştır. $\mathrm{Bu}$ testlerin sonucunda koltuğun FEA analizlerinde ön görülen deformasyonda kalıp, uygulanan kuvvetlere gerekli süre boyunca dayandığı görülmüştür.

Bu çalışmada üç noktadan destekli emniyet kemerinin iki sabit noktasını üzerinde taşıyan, kaza anında üzerine düşen kuvvetlere dayanımı artırılmış sürücü koltuğu mekanizması yapılmıştır.

Bu çalışma; Grammer Koltuk Sistemleri San. ve Tic. A.Ş. bünyesinde yapılan "FMVSS 210 Amerika Normuna Göre Ağır Ticari Araç Sürücü Koltuğu Geliştirilmesi" başlıklı yüksek lisans bitirme tezi faaliyetlerinden hazırlanmıştır.

\section{KAYNAKLAR}

1. Dassault Systems, Catia V5 Software (1994)

2. Deierlein, Bob. Fleet Equipment. (Aug 2000), Vol. 26 Issue 8, p48. 4p. 1 Diagram.Abstract: Focuses on design features and innovations made on truck seats for safety and driver retention in the United States. (AN: 3457526)

3. Gökhan Şendeniz, Ebru Pişgin (15-16 Mart 2016) Uludağ Üniversitesi V.Bilgilendirme ve Ar-Ge Günleri Proje Poster Sunumu, FMVSS 210 Amerika Normuna Göre Ağır Ticari Araç Sürücü Koltuğu Geliştirme Çalışmaları

4. Gökhan Şendeniz, Ferruh Öztürk (2014). 7. Otomotiv Teknolojileri Kongresi, 26-27 Mayıs 2014, Bursa. Yolcu Koltuklarında Topoloji Tasarım ve Yaklaşımları ile Optimizasyon

5. HyperWorks, Altair Opti Struct and Radioss Software (1985)

6. Skydel, Seth, Fleet Equipment. (Aug2008), Vol. 34 Issue 8, p40-42. 2p. The article focuses on the significance of ergonomics in seat design for safety, comfort and productivity. (A.N: 
Pişgin E., Solmaz E.: FMVSS 210 Normuna Göre Sürücü Koltuğu Geliştirilmesi

$34238410)$

7. U.S. Department of Transportation, National Highway Traffic Safety Administration, FMVSS 210 Regulation (1994).

8. United Nations, (2003). "Uniform provisions concerning the approval of vehicles with regard to safety belt anchorages", ECE R14 Regulation. 